\title{
STUDY OF CHRONIC EFFECTS OF VARYING DOSAGE OF X-RAYS ON HEPATOTOXICITY IN WISTAR ALBINO RATS
}

\author{
DEBAJIT $C^{1}{ }^{,}$RESHMA K $^{1 *}$, SUDHA K ${ }^{1}$, CHIRANTH $^{1}$, RAHUL $^{1}$ CHARU YADAV $^{1}$, RAJALAXMI RAI $^{2}$
}

${ }^{1}$ Department of Biochemistry, Kasturba Medical College, Manipal Academy of Higher Education, Manipal, Mangalore, India. ${ }^{2}$ Department of Anatomy, Kasturba Medical College, Manipal Academy of Higher Education, Manipal, Mangalore, India. Email: reshma.kc@manipal.edu

Received: 02 August 2017, Revised and Accepted: 17 November 2017

\section{ABSTRACT}

Objective: This study focuses on the chronic effects of various doses of radiation in the liver of albino Wistar rats subjected to irradiation using X-rays.

Materials and Methods: In the present study, albino Wistar rats were exposed to various doses of X-rays (4 Gy, 6 Gy, and 6.6 Gy) and the animals were observed for 30 days, following which they were sacrificed and liver tissue, being one of the targets of radiation-induced damage was analyzed for the oxidative stress markers, namely, reduced glutathione (GSH), superoxide dismutase (SOD), catalase and lipid peroxidation indicator, and malondialdehyde (MDA). Histopathological studies of the liver were also performed.

Results: Indicated that there was a significant increase in GSH and SOD levels in the animals exposed to radiation compared to controls (p<0.05). A decrease in these values was observed at 6.6 Gy compared to 6 Gy which was non-significant. However, there was a significant and consistent decrease in catalase and a similar increase in MDA with increased doses of X rays $(\mathrm{p}<0.05)$. Damage in hepatic structural architecture and disruption of central vein correlated positively with increased doses of X rays.

Conclusion: Our study strongly supports the hypothesis of the involvement of free radicals in radiation-induced damage to living systems

Keywords: Radiation, Oxidative stress, Hepatic tissue.

(C) 2018 The Authors. Published by Innovare Academic Sciences Pvt Ltd. This is an open access article under the CC BY license (http://creativecommons. org/licenses/by/4. 0/) DOI: http://dx.doi.org/10.22159/ajpcr.2018.v11i2.21766

\section{INTRODUCTION}

Ionizing radiation is defined as the energy that propagates in the form of photons (X-rays and $\gamma$ ) or in the form of subatomic particles $(\alpha, \beta$, neutrons, and protons) and are highly efficient cytotoxic agents. Exposure to ionizing radiation produces oxygen-derived free radicals termed as reactive oxygen species in the tissue which includes hydroxyl radical $\left(\mathrm{OH}^{-}\right)$and superoxide radical anion $\left(\mathrm{O}^{2-}\right)$, as well as other oxidants such as hydrogen peroxide $\left(\mathrm{H}_{2} \mathrm{O}_{2}\right)$. These species could arise on exposure to ionizing radiation [1,2] which is responsible for increasing levels of lipid peroxides and alterations in enzyme activities. Delayed effects are observed a month beyond acute exposure of radiation, mainly affecting the digestive system, cardiovascular system, eye, nervous system, reproductive system, urinary tract, respiratory system, musculoskeletal system, and endocrine system [3]. In terms of radiosensitivity, the liver ranks immediately below the kidney. It shares with these organs the fact that its functional subunits are arranged in parallel so that much larger doses are tolerated if only part of the organ is exposed. Liver tolerance is dose limiting only if the whole organ is irradiated, as in, for example, total-body irradiation before bonemarrow transplantation. The lifespan of a hepatocyte is about 1 year so that under normal conditions the cell renewal rate in the liver is very slow. Even large doses apparently are tolerated for a few months, but then hepatic function deteriorates progressively. Fatal hepatitis may result from a fractionated protocol of only 35 Gy (3,500 rad) if the whole organ is irradiated [4]. This work focuses on the chronic changes in the parameters of oxidative stress and histological changes of liver exposed to various dose of X-rays delivered through a linear accelerator.

\section{MATERIALS AND METHODS}

Irradiation

Animals were housed under standardized conditions for light and temperature. A commercially prepared diet and clean drinking water were provided ad libitum. All the animal experiments conducted in this study were in accordance with the Institute Animal Ethics Committee. Female albino Wistar rats of $8-10$ weeks of age $(150 \pm 10 \mathrm{~g})$ were placed in a well-ventilated Perspex box rectangular restrainer of size $24 \times 18 \mathrm{~cm}$ and a wall thickness of $1 \mathrm{~mm}$. Whole-body irradiation was administered to the experimental animals by LINAC having a field size of $40 \mathrm{~cm} \times 40 \mathrm{~cm}$ with a dose rate of $3.5 \mathrm{~Gy} / \mathrm{min}$ and distance from the source to subject of $100 \mathrm{~cm}$. The dosimetry of LINAC was carried out by the International Atomic Energy Agency, Dosimetry and Medical Radiation Physics Section, Austria. The radiation exposure was carried out at the Department of Radiotherapy, KMC Hospital, Attavar, Mangalore. The rats which were not irradiated served as the control (Group 1) and other irradiated groups were 4 Gy (Group 2), 6 Gy (Group 3), and 6.6 Gy (Group 4) with five rats in each group.

Preparation of tissue homogenate and biochemical estimations The rats were sacrificed after 1 month of post-radiation by anaesthetizing with diethyl ether, the liver was carefully dissected out; extracted; $1 \mathrm{~g}$ of the tissue was weighed and homogenized with $10 \mathrm{~mL}$ of $0.4 \mathrm{M}$ phosphate buffer $\mathrm{pH}$ (7.4). The homogenate is then centrifuged at $10,000 \mathrm{rpm}$, and $1 \mathrm{~mL}$ of the supernatant was used for the assay.

Reduced glutathione (GSH)

GSH was estimated by the method of Beutler et al. [5] where the color produced by reaction of GSH with DTNB was measured spectrophotometrically at $412 \mathrm{~nm}$. Results were expressed as $\mu \mathrm{mol} / \mathrm{g}$ wet tissue.

\section{Malondialdehyde (MDA)}

MDA formed by the breakdown of polyunsaturated fatty acids serves as a convenient index to determine the extent of lipid peroxidation reacts with TBA to give a pink color which was read at $535 \mathrm{~nm}$ [6]. Results were expressed as nmol/g wet tissue. 
Superoxide dismutase (SOD)

The estimation of SOD enzyme was carried out by Beauchamp and Fridovich method. The substrate used for the assay consists of nitro blue tetrazolium chloride which reacts with superoxide anions produced on illumination of riboflavin in the presence of methionine as an electron donor, to produce formazan which is a blue-colored complex [7]. The activity of SOD was expressed in U/g protein.

\section{Catalase}

Catalase activity was measured in terms of the decomposition of hydrogen peroxide $\left(\mathrm{H}_{2} \mathrm{O}_{2}\right)$ into water molecule, which was measured as decreased inabsorbance at $240 \mathrm{~nm}$. The catalase activity was expressed as $\mathrm{U} / \mathrm{g}$ protein, i.e., $1 \mu$ mole of $\mathrm{H}_{2} \mathrm{O}_{2}$ converted into $\mathrm{H}_{2} \mathrm{O}$ in 1 min [8].

\section{Total protein of liver tissue by Lowry's method}

Protein estimation was carried out by the method of Lowry et al. Proteins react with alkaline copper reagent and Folin's reagent to form a colored complex which was measured after $30 \mathrm{~min}$ at $540 \mathrm{~nm}$ [9].

\section{Histopathogical analysis}

A part of the liver, kidney, and ovary was fixed in $10 \%$ formalin for histological examination. The sections were stained with hematoxylin and eosin ( $\mathrm{H}$ and $\mathrm{E})$ mounted with Canada Balsam and examined microscopically.

\section{Statistical analysis}

Statistical analysis was performed using SPSS version 16.00. All data were expressed as meantstandard error of the mean. Comparison between the groups was performed by ANOVA, and intergroup was done with GAMES HOWELL as post hoc test; $\mathrm{p}<0.05$ was considered as statistically significant. The histopathological damage of liver tissue was scored as none, light, moderate, and severe.

\section{RESULTS}

Antioxidants and oxidative stress marker in liver

GSH: Significant increase in reduced GSH level was observed in Group 2, Group 3, and Group 4 when compared to control groups $(\mathrm{p}<0.05)$. Between the groups, there was a significant decrease as dose increased to Group 2, Group 3, and Group 4 ( $\mathrm{p}<0.05)$.

SOD: There was a consistent increase in SOD activity in Group 2 and Group 3 when compared with control, but in the Group 4, level decreased significantly when compared to Group 1, Group 2, and Group 3.

Catalase: A consistent decrease in the values of catalase activity with an increase in radiation dose was found when compared with control group which was found to be statistically significant $(\mathrm{p}<0.05)$, and there was a significant decrease $(\mathrm{p}<0.05)$ between the groups.

MDA: There was consistent increase with increase in radiation dose when compared with control group and also among the groups, it was statistically significant $(\mathrm{p}<0.05)$.

A histopathological feature of control shows normal hepatic structural architecture with proper central (Fig. 1) vein, but a mild disruption of central vein (C) along with mild lymphocytic infiltration (I) was seen in Group 2 (Fig. 2). In Group 3, a moderate disruption and dilatation of central vein along with ballooned and disrupted hepatocytes were observed (Fig. 3) when compared to Group 4 (Fig. 4) hepatic tissue with severe disruptions of central vein and hepatocytes along with irregular sinusoids.

\section{DISCUSSION}

\section{Tissue levels of antioxidants and oxidative stress marker} Liver

According to earlier studies involving exposure of living beings, especially plants, to radiations, it was reported that, with an increase in the dosage of radiation, the amount of free radicals produced proportionately increased, thereby inducing the antioxidant production, resulting in a concomitant increase in antioxidants [10]. In our study, we attempted to evaluate the chronic effects of different doses of radiation on the enzymes involved in neutralizing oxidative stress and also oxidative stress marker in albino Wistar rat model. In the present study, GSH levels and SOD were found to increase after total body irradiation (TBI) of 4 Gy and 6 Gy compared

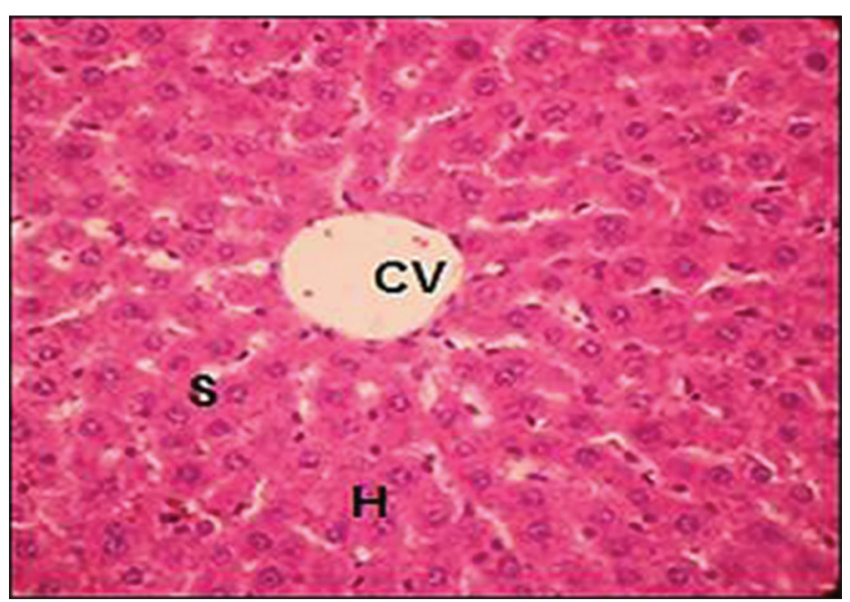

Fig. 1: Control (Group 1) shows normal hepatic structural architecture

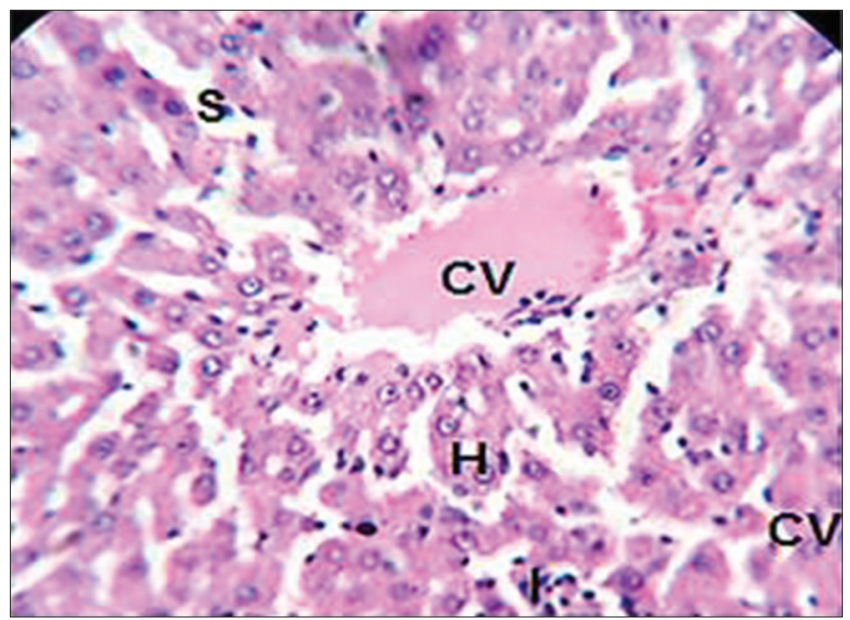

Fig. 2: 4Gy-(Group 2) hepatic tissue shows mild disruption of central vein (C), along with mild lymphocytic infiltration (I)

Table 1: Liver tissue levels of antioxidant and oxidative stress parameter in each group under chronic effects of radiation

\begin{tabular}{llll}
\hline Tissue levels & Group 1 & Group 2 & Group 3 \\
\hline Reduced GSH ( $\mu$ g/g of wet tissue) & $1171.74 \pm 342.38$ & $1959.98 \pm 92.25^{*} \mathrm{a}$ & $5985.22 \pm 1670.78 * \mathrm{~b}$ \\
SOD (U/g of protein) & $7.37 \pm 1.25$ & $7.92 \pm 0.47$ & $3.87 \pm 0.7 *$ \\
Catalase (U/g of protein) & $21.83 \pm 1.76$ & $15.81 \pm 1.74 * \mathrm{a}$ & $10.43 \pm 4.11 *$ \\
MDA (n mol/g of wet tissue) & $0.50 \pm 0.08$ & $1.05 \pm 0.33^{*} \mathrm{a}$ & $1.91 \pm 0.05^{*} \mathrm{~b}$ \\
\hline
\end{tabular}

${ }^{*} \mathrm{p}<0.05$ was significant groups versus control, a - Group 2 versus Group 3, b - Group 3 versus Group 4, c - Group 2 versus Group 4, GSH: Glutathione, SOD: Superoxide dismutase, MDA: Malondialdehyde 


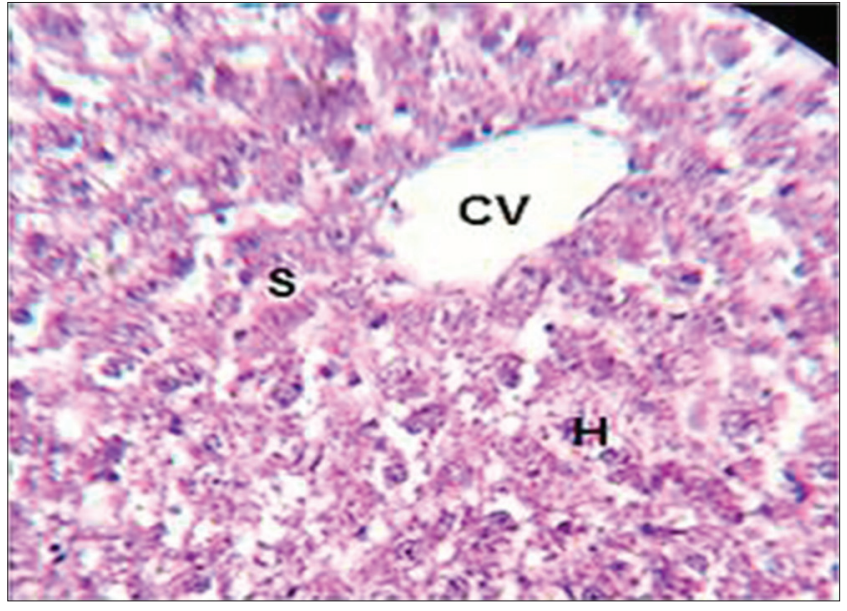

Fig. 3: 6 Gy-(Group 3) a moderate disruption and dilatation of central vein along with ballooned and disrupted hepatocytes

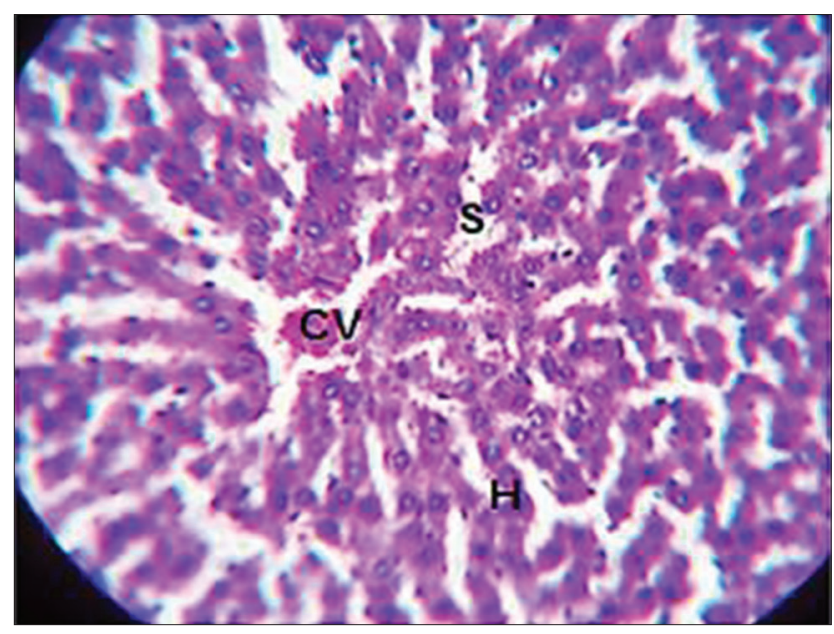

Fig. 4: 6.6 Gy-(Group 4) severe disruptions of central vein and hepatocytes along with irregular sinusoids

to the control (Table 1). This is in agreement with results obtained by Yamaoka et al. [11] and Kojima et al. [12]. There is an increase in GSH within the cells which may play an important role in protection against the oxidant and ionizing radiation-induced DNA damage and in preserving nuclear proteins in a reducing environment for gene transcription during the cell cycle progression and therefore may provide a protection against free radical-mediated damage and oxidative stress in liver.

It has been reported that radiation causes SOD activity to be increased to eliminate superoxide radicals in the liver and kidney; the resulting $\mathrm{H}_{2} \mathrm{O}_{2}$, if not neutralized, may undergo Fenton/Haber-Weiss reaction or may react with $\mathrm{NO} \bullet$ leading to the formation of $\mathrm{OH} \bullet$ and $\mathrm{ONOO}$ - radicals, respectively, which are known for their detrimental effect on the biological system. The $\mathrm{H}_{2} \mathrm{O}_{2}$ has higher reactivity causing increased activity of GSH peroxidase. This high circulating $\mathrm{H}_{2} \mathrm{O}_{2}$ leads to a cascade of other free radicals which caused cell damage. To protect this lethal damage, the tissue synthesizes more of endogenous GSH. The increase in SOD and GSH in chronic irradiated conditions reflects the resultant oxidative damage.

Cellular GSH peroxidase and GSH reductase are part of redox system of GSH and remove hydrogen peroxide generated from cytoplasm and mitochondria by oxidizing tripeptide GSH to form Oxidised glutathione (GSSG) which in turn gets converted to GSH for further scavenging of the free radicals. Results of GSH and SOD with respect to liver tissue support this hypothesis up to a dose of $6 \mathrm{~Gy}$, thereafter a decrease in both parameters is observed at 6.6 Gy which indicates that the maximum oxidative damage occurs at this dose range [13]. The activity of catalase a scavenger of $\mathrm{H}_{2} \mathrm{O}_{2}$ is also found to be least at 6.6 Gy.

Radiation may have induced the production of SOD, but a similar induction is not observed with respect to catalase. There is a significant decrease in the activity of catalase in Group 2, Group 3, and Group 4 compared to control. This is in contradiction with results obtained by Shridharan and Shyamaladevi [14], but similar results of decreasing activity were obtained by Anjali et al. GSH-Px (GSH peroxidase), Activity may be higher in liver tissue as compared to the activity of catalase which indicates the sparing action of GSH-Px over catalase as both enzymes share the same function of detoxifying $\mathrm{H}_{2} \mathrm{O}_{2}$

On comparing, GSH levels and activity of SOD were found to decrease significantly in the liver in Group 4 along with a significant decrease in the activity of catalase. These changes are also in agreement with the previous studies on Syrian hamsters done by Feurgard et al. [15] and on mice as reported by Agrawal et al. [16].

Lipid peroxidation is believed to be an important cause of destruction and damage caused to cell membranes. It has been suggested to be a contributing factor to the development of tissue damage. In the literature, increased levels of MDA are used as a marker of lipid peroxidation. In our study, we detected increased levels of MDA which is significantly high in liver tissue. MDA concentration has significantly increased following increased dose of radiation. An increase in MDA levels shows the development of oxidative stress by ionizing radiations. This observation is in agreement with the study of Kumar et al. [17].

The histological results obtained in the liver tissue show a maximum damage at 6.6 Gy. Histological changes observed in the liver of reptile Uromastix hardwickii after exposure to three doses (i.e., 2.25, 4.50, and $9.00 \mathrm{~Gy}$ ) of gamma radiations from Cobalt-60 source included cytoplasmic degranulation, swollen hepatocytes, pyknosis, and increase in bile pigmentation [18]

The tissue levels of MDA, a marker of lipid peroxidation, are also found to be maximum at $6.6 \mathrm{~Gy}$. Therefore, oxidative damage is well correlated with tissue damage, but a similar correlation is not observed with respect to antioxidant defense mechanisms. Although a rise is seen in GSH and SOD at 4 Gy and $6 \mathrm{~Gy}$, the rise is not consistent at $6.6 \mathrm{~Gy}$, instead a further decrease is observed at $6.6 \mathrm{~Gy}$. The destruction seen beyond exposure to 6 Gy may reflect a post-threshold functional breakdown of the existing antioxidant system within the cellular milieu. The hepatocellular damage caused by radiation is reflected by the pronounced activity of aminotransferases, phosphatases, lactate dehydrogenases, and creatine kinase in the blood plasma, which are all indicative of cellular leakage and loss of functional integrity of the liver cell membrane [14].

\section{CONCLUSION}

In this study, Wistar albino rats were exposed to increasing doses of single fraction TBI. Following TBI, increased oxidative stress was noted, as reflected by increased MDA levels with increasing doses of radiation which correlated well with tissue damages as observed by histopathology.

\section{REFERENCES}

1. Bashan N, Kovsan J, Kachko I, Ovadia H, Rudich A. Positive and negative regulation of insulin signaling by reactive oxygen and nitrogen species. Physiol Rev 2009;89:27-71.

2. Saini MA, Bala MA, Farooqi HU, Abdin MZ, Prasad JA. Renoprotective activity of hippopahe leaf extract in total body 60Co-gamma-irradiated mice: An oxidative and histopathology study. Int J Pharm Pharm Sci 2014;6:161-6.

3. Uma PD, Nagarthnam A, Satish BS, editors. Introductionto radiation biology. New Delhi: B.I. Churchill Livingstone Pvt. Ltd.; 2000.

4. Hall EJ, Giaccia AJ. Dose response Relationships for normal tissues. Radio Biology for Radiobiologists. $6^{\text {th }}$ ed., Cha. 18. Philadelphia, PA: Lippincott Williams \& Wilkins; 2006. 
5. Beutler E, Duron O, Kelly BM. Improved method for the determination of blood glutathione. Journal of Laboratory and Clinical Medicine 1963; 61:882-888.

6. Sardar S, Chakraborty A, Chatterjee M. Comparative effectiveness of vitamin D3 and dietary vitamin $\mathrm{E}$ on peroxidation of lipids and enzymes of the hepatic antioxidant system in sprague - Dawley rats. Int J Vitam Nutr Res 1996;66:39-45.

7. Beauchamp C, Fridovich I. Superoxide dismutase: Improved assays and an assay applicable to acrylamide gels. Anal Biochem 1971;44:276-87.

8. Aebi H. Catalase in vitro. Methods Enzymol 1984;105:121-6.

9. Wilson K, Walker J. Practical Biochemistry: Principles and Techniques. Cambridge: University Press; 2000.

10. Rajurkar NS, Gaikwad KN, Razavi MS. Evaluation of free radical scavenging activity of justiciaadhatoda: A gamma radiation study. Int $\mathrm{J}$ Pharm Pharm Sci 2012;4:93-6.

11. Yamaoka K, Edamatsu R, Mori A. Increased SOD activities and decreased lipid peroxidation induced by low dose $\mathrm{X}$ irradiation in rat organs. Free Radic Biol Med 1991;11:299-306.

12. Kojima S, Matsuki O, Nomura T, Kubodera A, Honda Y, Honda S, et al. Induction of mRNAs for glutathione synthesis-related proteins in mouse liver by low doses of gamma-rays. Biochim Biophys Acta 1998;1381:312-8.
13. Srinivas C, Kumar A, Rai R, Kini J, Kumarchandra R. Standardization of mean lethal dose (LD50/30) of X-rays using linear accelerator (LINIAC) in albino wistar rat model based on survival analysis studies and hematological parameters. Res J Pharm Biol Chem Sci 2015;6:1215-9.

14. Sridharan S, Shyamaladevi CS. Protective effect of N-acetyl cysteine against gamma ray induced damages in rats - Biochemical investigation. Ind J Exp Biol 2002;40:181-6.

15. Feurgard C, Boehler N, Ferezou J, Serougne C, Aigueperse J, Petal G. Ionizing radiation alters hepatic cholesterol metabolism and plasma lipoproteins in Syrian hamster. Radiation alters hepatic cholesterol metabolism and plasma lipoproteins in Syrian hamster. Int J Radiat Biol 1999;75:757-66.

16. Agrawal A, Chandra D, Kale RK. Radiation induced oxidative stress: II studies in liver as a distant organ of tumor bearing mice. Mol Cell Biochem 2001;224:9-17.

17. Kumar A, Kumarchandra R, Rai R, Rao BS. Radiomodulatory role of Psidium guajava leaf extracts against X-ray induced genotoxicity, oxidative stress and apoptosis inalbino wistar rat model. J Appl Pharm Sci 2016;6:58-65.

18. Gupta ML, Devi PU. Response of Piscine liver to external gama irradiation. Radiobiol Radiother 1990;31:289-92. 